\title{
Programme « Ville de Delphes »
}

Campagne d'inventaire des murs

Jean-Marc Luce

\section{(2) OpenEdition \\ Journals}

Édition électronique

URL : https://journals.openedition.org/baefe/4464

DOI : $10.4000 /$ baefe.4464

ISSN : 2732-687X

Éditeur

ResEFE

Référence électronique

Jean-Marc Luce, «Programme « Ville de Delphes » » [notice archéologique], Bulletin archéologique des Écoles françaises à l'étranger [En ligne], Grèce, mis en ligne le 20 décembre 2021, consulté le 22 décembre 2021. URL : http://journals.openedition.org/baefe/4464; DOI : https://doi.org/10.4000/ baefe.4464

Ce document a été généré automatiquement le 22 décembre 2021.

\section{(c) (i) (9)}

Le Bulletin archéologique des Écoles françaises à l'étranger est mise à disposition selon les termes de la Licence Creative Commons Attribution - Pas d'Utilisation Commerciale - Pas de Modification 4.0 International. 


\title{
Programme « Ville de Delphes »
}

\author{
Campagne d'inventaire des murs
}

Jean-Marc Luce

\section{NOTE DE L'AUTEUR}

Date précise de l'opération : 2-15 août 2021, puis 15-21 août 2021

Autorité nationale présente : Athanasia Psalti, Éphore de Delphes

Numéro de mission : D10

Composition de l'équipe de terrain : Ont participé à la campagne, outre le

responsable de la mission, Frédérique Baltzinger, archéologue bénévole, Lara Sageaux, jeune doctoresse de l'Université de Toulouse Jean-Jaurès, Julian Brouet, doctorant à l'Université Toulouse Jean-Jaurès, Charlotte Goulet, stagiaire topographe-architecte.

Partenariats institutionnels : CRATA Culture, Représentations, Archéologie, Textes Antiques (Unité de recherche PLH- Université Toulouse Jean Jaurès)

Établissement éditeur : EFA

Établissements porteurs de l'opération : EFA

Chroniques de l'EfA :

Delphes. La ville 2019

Delphes. La ville 2017

1 La campagne 2021 consacrée au programme Ville de Delphes s'est déroulée en deux phases, la première, du 2 au 15 août, avec petite équipe dynamique de cinq personnes, et une semaine supplémentaire à deux pour compléter les photos et quelques descriptions et relevés. Organisée par l'EFA, la mission a été soutenue par l'équipe de recherche CRATA (Unité de recherche PLH- Université Toulouse Jean Jaurès). L'emprise de la campagne a concerné l'espace entre le péribole Ouest du sanctuaire d'Apollon et le quartier de l'hérôon de Blum (fig. 1).

2 Les objectifs étaient de poursuivre l'inventaire des murs du site dans une zone qui est l'une des moins étudiées de Delphes et d'en faire un relevé au 1:50. Elle se subdivise, 
sur le plan géomorphologique, de trois secteurs. Le premier (zone 1), en partant de l'Est, est inséré dans une zone qui se trouve à peu près au même niveau que le sanctuaire, avec une pente assez raide, sur du flysch, avec de grandes accumulations de terre, la second (zone 2), plus à l'Ouest, est une hauteur constituée principalement d'un substrat en conglomérat avec des rochers en calcaire gris tombés dessus, voire dedans. La troisième zone (zone 3), encore plus à l'Ouest, retrouve les niveaux du sanctuaire, à nouveau sur un substrat en flysch.

Fig. 1. Espace entre le péribole Ouest du sanctuaire d'Apollon et le quartier de l'hérôon.

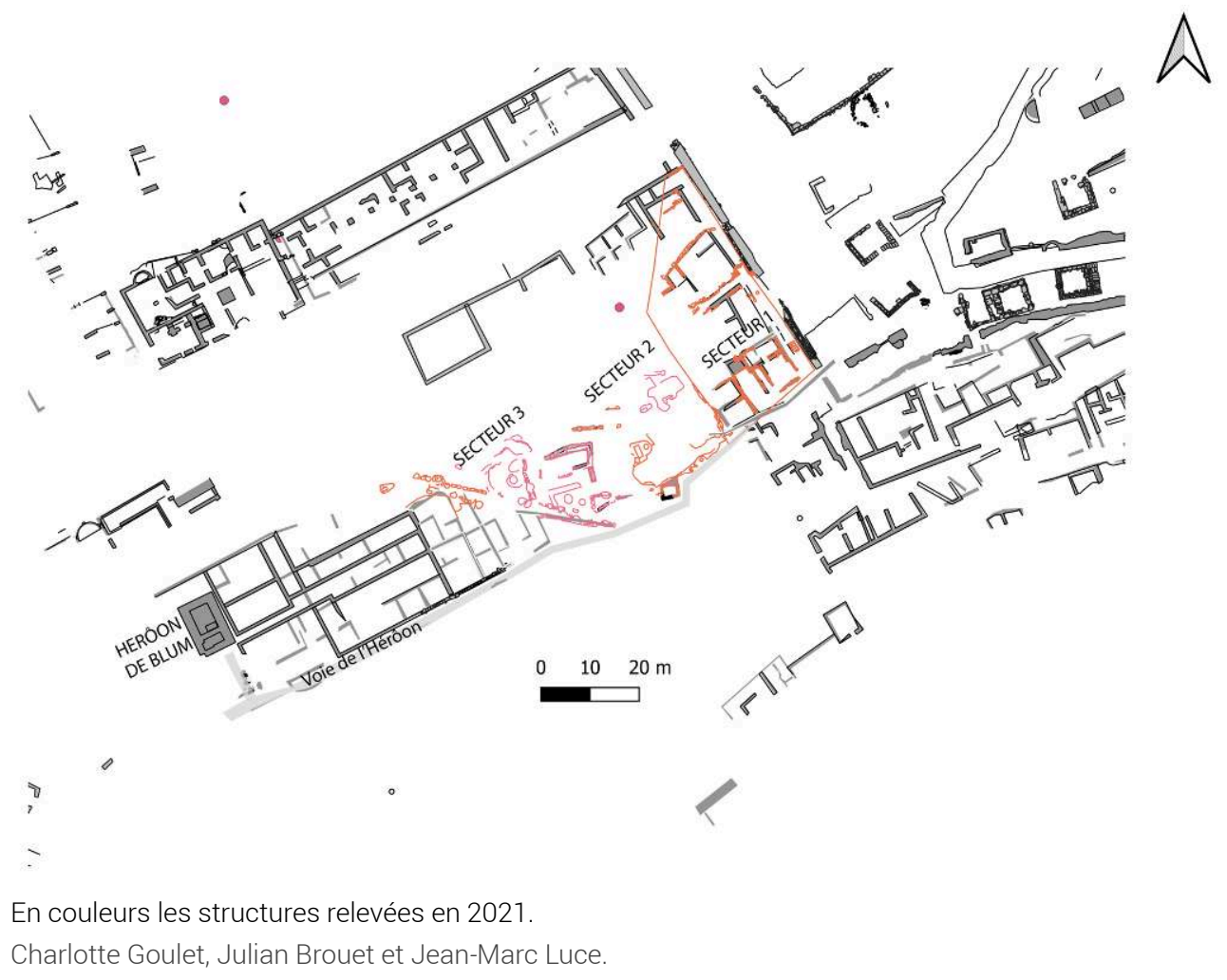

3 Nettoyages, descriptions et relevés nous ont permis de compléter les plans existants et de faire quelques nouvelles identifications :

\section{La nécropole mycénienne}

$4 \quad$ La Grande fouille avait mis au jour plusieurs tombes mycéniennes dans les zones 2 et 3 qui sont mentionnées dans PERDRIZET 1908, p. 5-6, d'autres sont entièrement inédites, mais mentionnées dans l'article de MÜLLER 1992, p. 493-94. On trouve aussi dans cet article un plan très général, avec les emplacements des tombes indiqués par des cercles (fig. 2). 
Fig. 2. Plan des vestiges mycéniens dressé par Sylvie Müller.

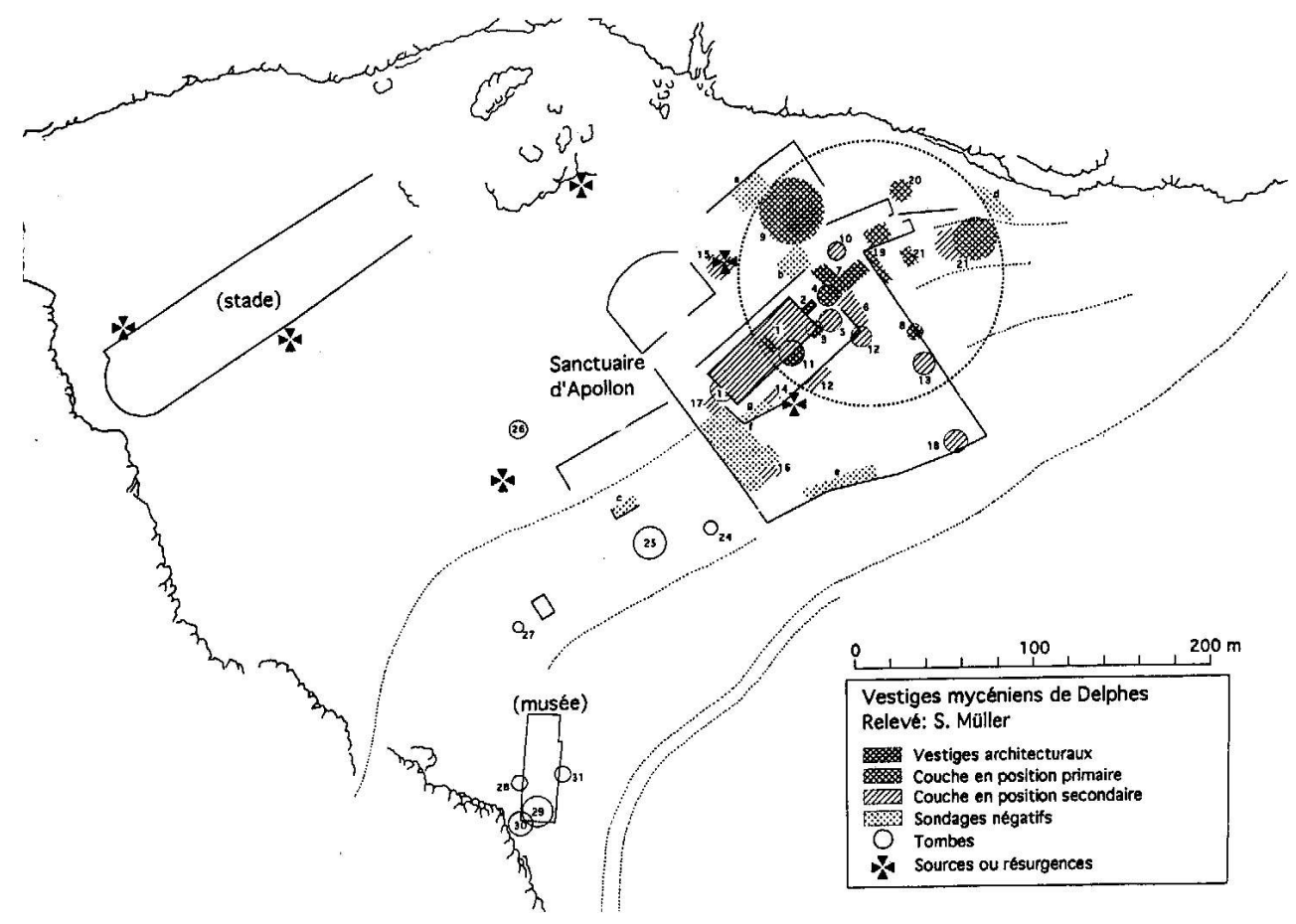

MÜLLER 1992, p. 456, fig. 5.

Le travail que nous avons fait a permis :

1. de constituer un plan général de la nécropole mycénienne (fig. 9), en y plaçant les tombes dont on peut voir encore aujourd'hui les vestiges, et celles sur la localisation desquelles on ne dispose que d'information générale sur la localisation. Ont pu être identifiées sur le terrain les tombes suivantes (avec notre numérotation) :

- La tombe 0-515 (fig. 3), au pied de la zone 2, tombe rupestre, avec chambre secondaire à l'Ouest, creusée dans le substrat en conglomérat ${ }^{1}$. La cavité creusée dans le substrat en conglomérat s'est conservée. 
Fig. 3. Tombe 0-115.

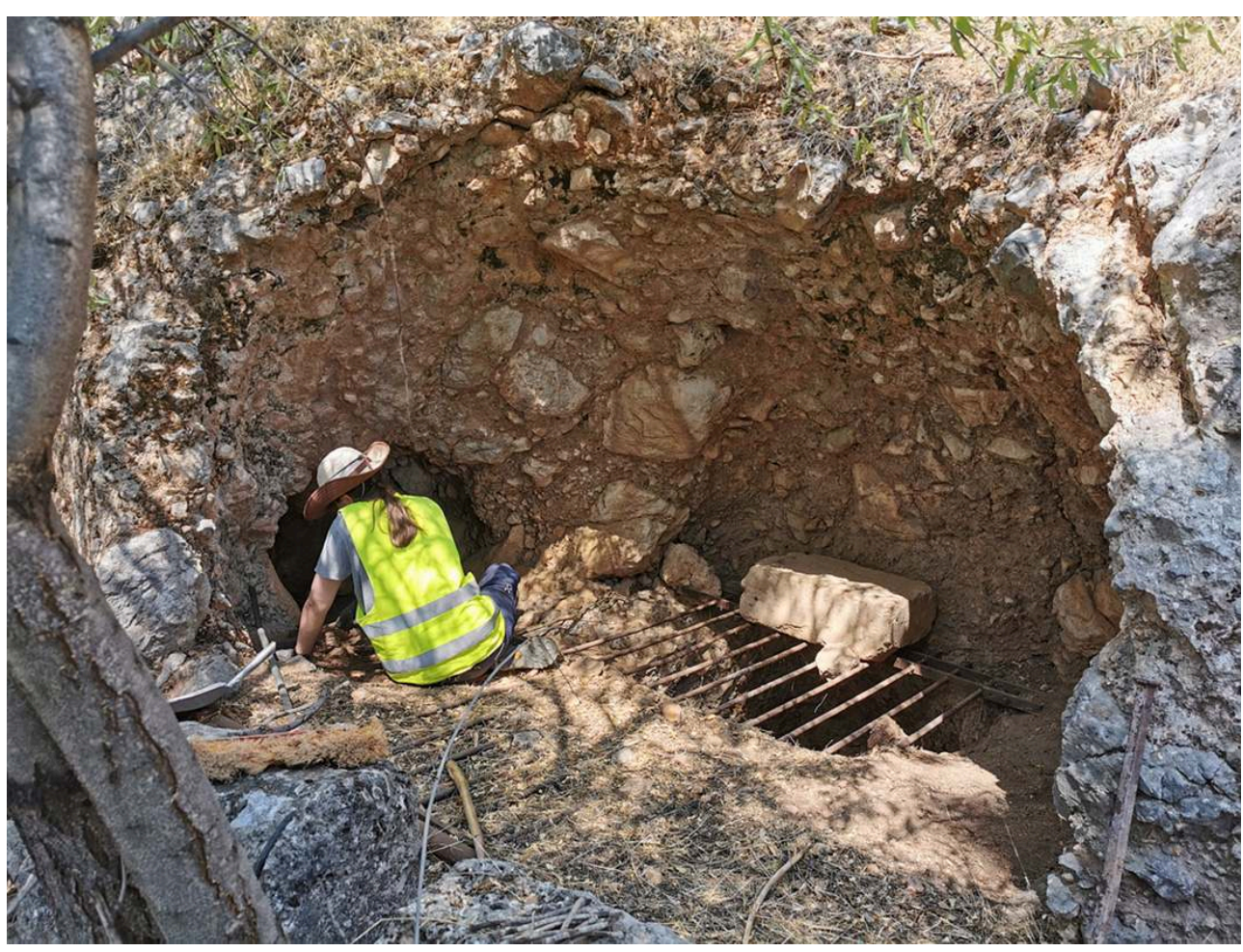

Cl. Jean-Marc Luce.

- La tombe rupestre 0-522 (fig. 4) ${ }^{2}$. Le départ de la voûte, creusée également dans le substrat. 
Fig. 4. Tombe rupestre 0-522 et la fontaine à l'arrière.

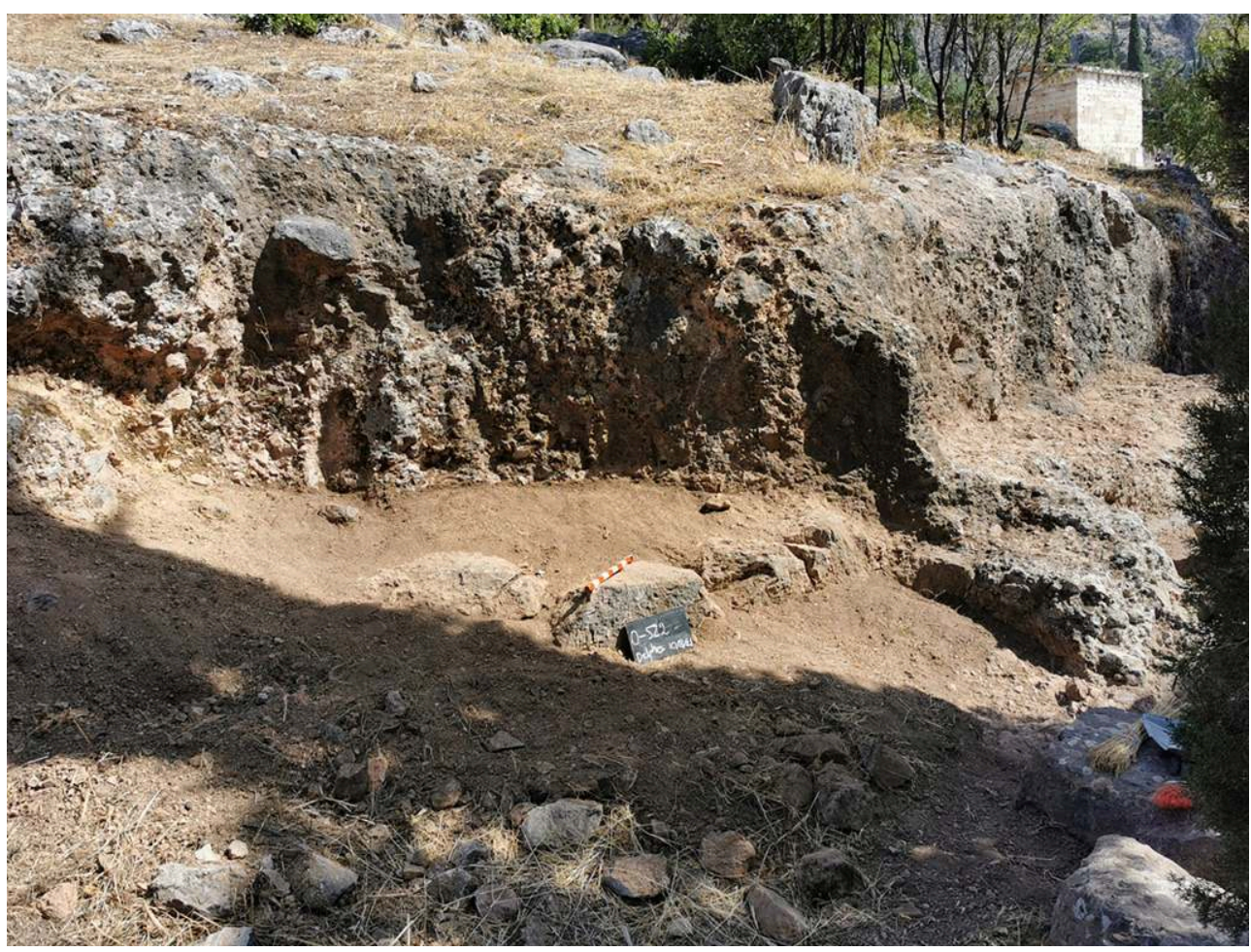

Cl. Jean-Marc Luce.

- La grande tombe à dromos 0-800 (fig. 5 et 6) ${ }^{3}$. Un puits avait été creusé à l'Ouest du dromos près du stomion. Le blocage des très grosses pierres qui fermait l'entrée du dromos est encore en place et bien visible, ainsi que le puits (plus de cinq mètres de profondeur). Le mur Sud-Est du dromos est également visible. Pour le reste, on ne devine que la forme de la tombe, les parois, creusées dans le flysch, s'étant désintégrées. Une sorte de grotte est apparue à l'arrière de la tombe, bien visible depuis la voie actuelle inférieure, mais n'est peut-être qu'un développement récent dû à l'érosion. La matière est en effet très friable, ce qui explique l'effondrement de la voûte très peu de temps après la fouille. La chambre est aujourd'hui recouverte de pierres tombées des soutènements modernes au-dessus, en partie effondrés. 
Fig. 5. Plan de la tombe, selon Perdrizet.

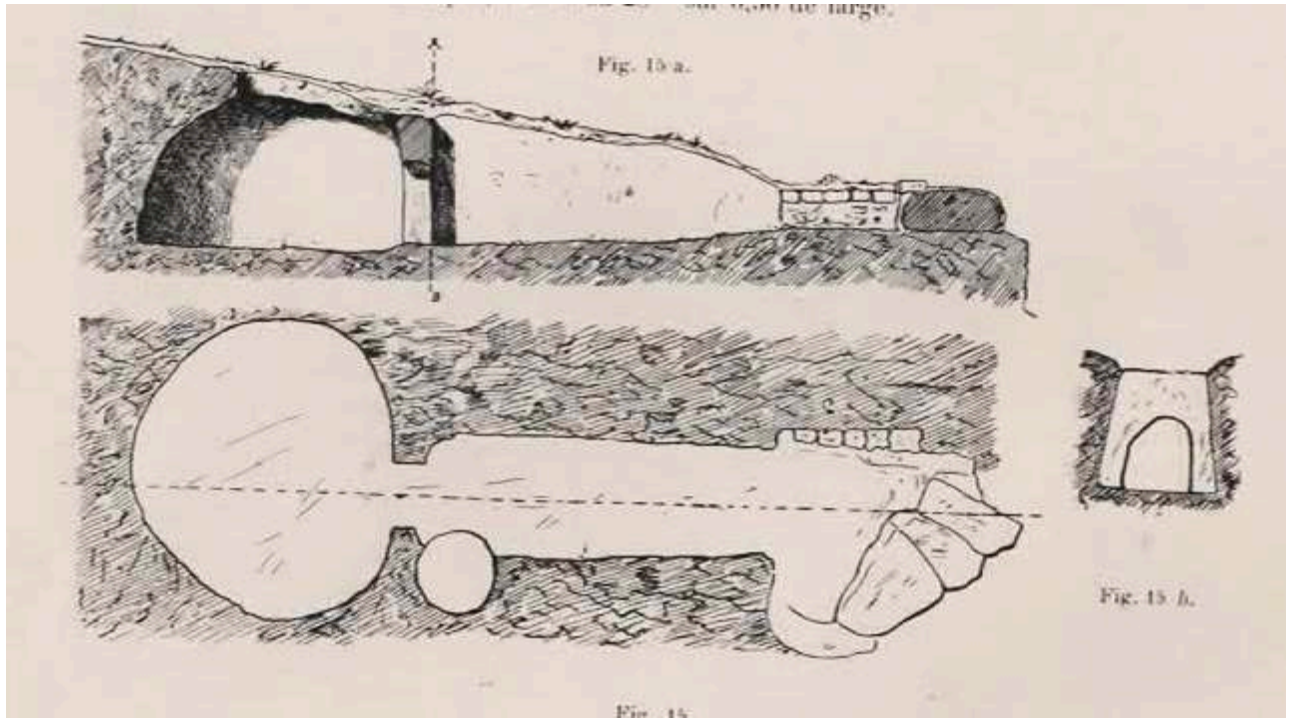

PERDRIZET 1908, fig. 15.

Fig. 6. Dromos de la tombe $0-800$ vue du Nord.

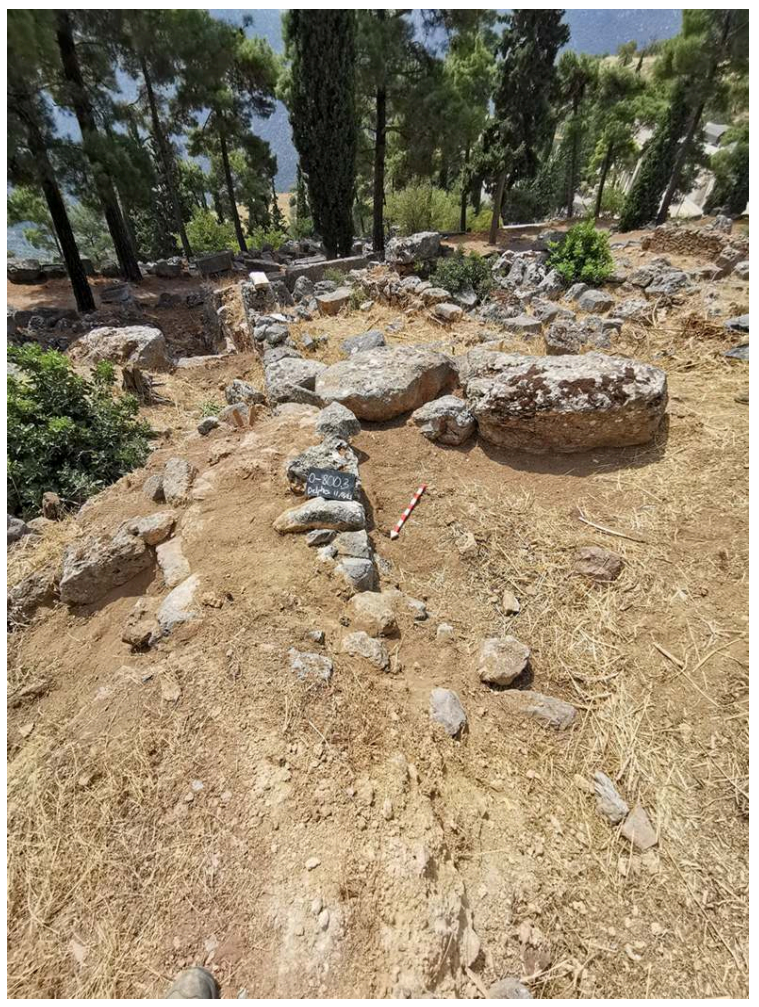

Cl. Jean-Marc Luce. 
Fig. 7. Départ d'une voûte de tombe mycénienne renforcée par un fragment de pithos.

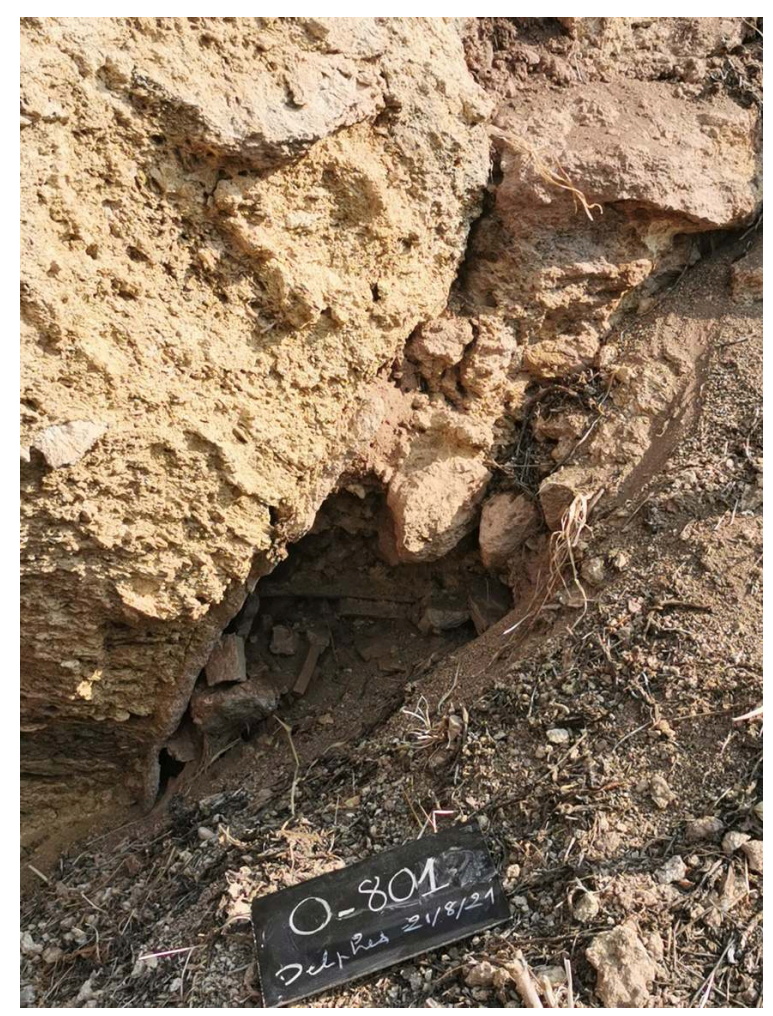

Cl. Jean-Marc Luce.

6 Perdrizet mentionne cinq tombes «à peu de distance les unes des autres », mais ne publie les plans que de trois d'entre elles (=0-800, 0-522, 0-515). Pour situer les deux autres, nous en sommes réduits aux hypothèses. Toutefois, deux creusements dans le flysch bordent la tombe au dromos, l'un vers l'Est, incertain toutefois (0-806), l'autre vers l'Ouest (0-801), pourraient appartenir aux tombes mycéniennes manquantes. Si ce n'est pas le cas, la forme des creusements suggère néanmoins que ce sont les vestiges de tombes mycéniennes, au moins celle de l'Ouest. Contre la paroi de flysch, le départ d'une voûte a même été renforcé par un gros fragment de pithos (fig. 7). Des tessons à l'intérieur pourraient être mycéniens.

7 Le long de la voie de l'Hérôon, un long mur 0-704 construit à diverses époques (voir ci-dessous) longe une zone légèrement en hauteur, qui s'élève sur un substrat principalement en flysch, en conglomérat à l'Ouest, bordant au sud le quartier de l'Hérôon de Blum. Cette voie existait à l'époque mycénienne, car elle relie les tombes 0-515 et 0-522 aux tombes découvertes sous le musée. Or, cette bordure, offrant une sorte de front de taille rocheux, dans la roche particulièrement tendre du flysch, se prête au creusement de chambres funéraires. Comme nous avons affaire à une nécropole et non à des tombes isolées, il paraît légitime de rechercher les traces éventuelles d'autres tombes mycéniennes. Pour les découvrir, nous disposons d'un indice : le mur, à partir de 704.5, est en moellons, mortier et fragments de terre cuite architecturale. Or par endroits, cet appareil laisse la place à de gros blocs sans parement, sans mortier, sans terres cuites dans les joints. Quand il y a un creusement 
dans le roc derrière, on peut y voir les blocs de fermeture de chambres funéraires. Nous proposons ainsi d'identifier trois nouvelles tombes:

- Tombe 0-709 (fig. 8) : trois gros blocs, dont un tombé au Nord, et dans la foulée à l'ouest, un appareil de type mycénien (taille des blocs absence de parement). Derrière le roc est creusé pour former une chambre.

Fig. 8. Tombe 0-709.

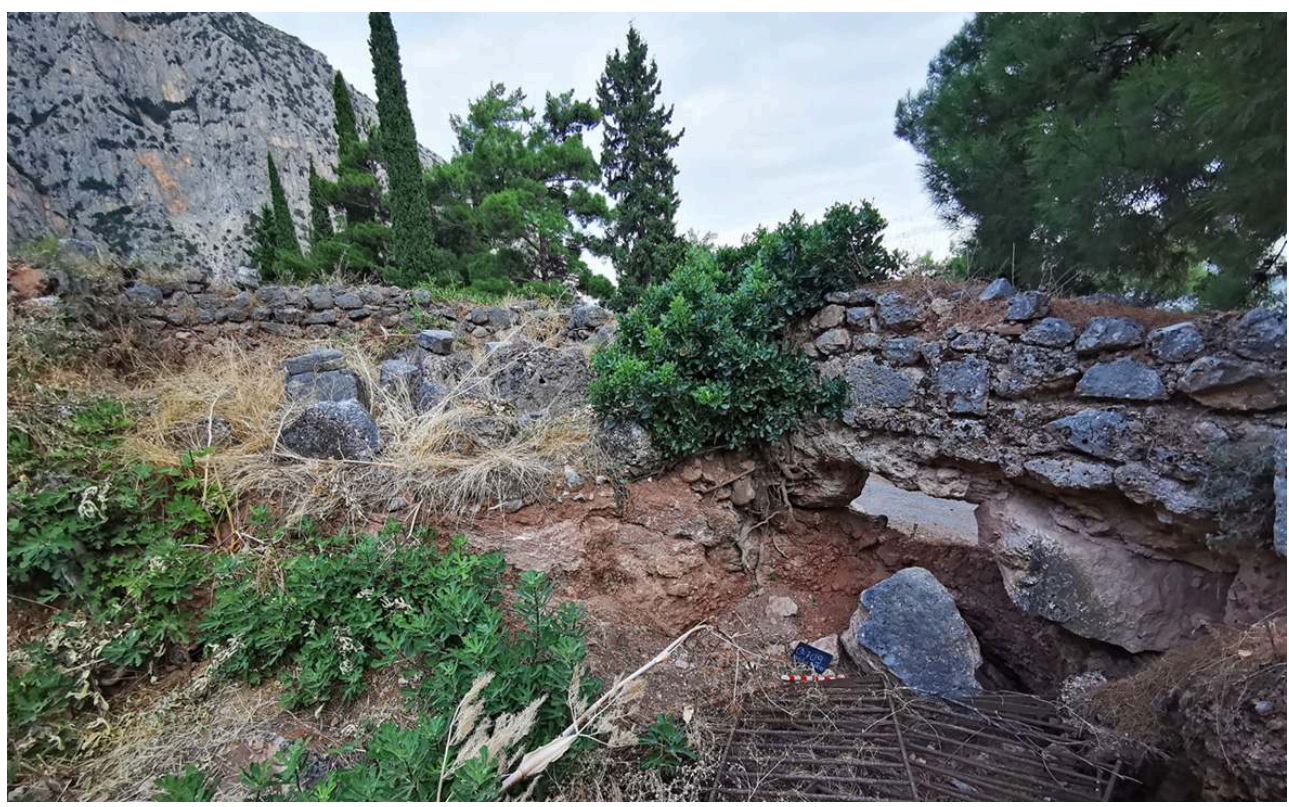

Creusement derrière de très gros blocs. Probablement une chambre funéraire mycénienne derrière le comblement qui en fermait l'entrée.

Cl. Jean-Marc Luce.

- 0-713: creusement du rocher juste à l'Ouest de 0-709.

- Tombe 707.2. Gros blocs avec un prolongement de blocs de type mycénien à l'Est. Le creusement derrière n'est pas visible.

8 À ces tombes, s'ajoutent celles dont aucune trace n'est aujourd'hui visible, mais qui sont situées grossièrement sur le plan (fig. 9):

- La tombe de la tranchée près du théâtre : tombe à chambre avec long dromos ${ }^{4}$.

- La tombe dite de «Pylaea » à l'Ouest de l'Hérôon de Blum, aujourd'hui recouverte par des remblais de fouilles ${ }^{5}$.

- Les tombes découvertes sous le musée ${ }^{6}$.

\section{Les voies mycéniennes}

9 Les deux premières tombes qui, selon Perdrizet, étaient dépourvues de dromos (mais ce dernier a pu disparaître à l'occasion des remaniements plus tardifs), longeaient la voie actuelle, qui sort de la porte A' du sanctuaire, au pied de la colline en conglomérat du secteur 2. Cette voie devait donc déjà exister à l'époque mycénienne et relier la nécropole Ouest (une tombe à chambre a été trouvée par P. Amandry près de Marmaria). En revanche, la tombe au dromos et les deux qui l'entourent se situent plus haut dans le secteur 3. Elles étaient donc accessibles par une rue montant depuis un point légèrement à l'Ouest de la tombe 0-515. Cette rue n'avait jamais été identifiée, 
mais nos nettoyages et observations ont permis de la retrouver, car elle est en grande partie conservée (fig. 10 et 12). Elle partait en oblique, rejoignant l'entrée de la tombe 800 , marquée clairement par le blocage du dromos, et se poursuivait vers le Nord-Ouest. Le soutènement Sud comporte encore à l'Est (0-524.1) quatre blocs en place d'un appareil cyclopéen très similaire à celui de la fortification de Chrysso. Après un tronçon remanié à plusieurs époques et reconstruit légèrement en avant, on retrouve à l'Ouest un gros bloc et un mur de facture mycénienne. Le soutènement Nord est conservé sur environ $7,40 \mathrm{~m}$. Au-delà de la tombe 801 , le chemin se poursuivait, mais on ne suit pas les restes de l'appareil mycénien.

Fig. 9. Plan de la nécropole mycénienne Ouest.

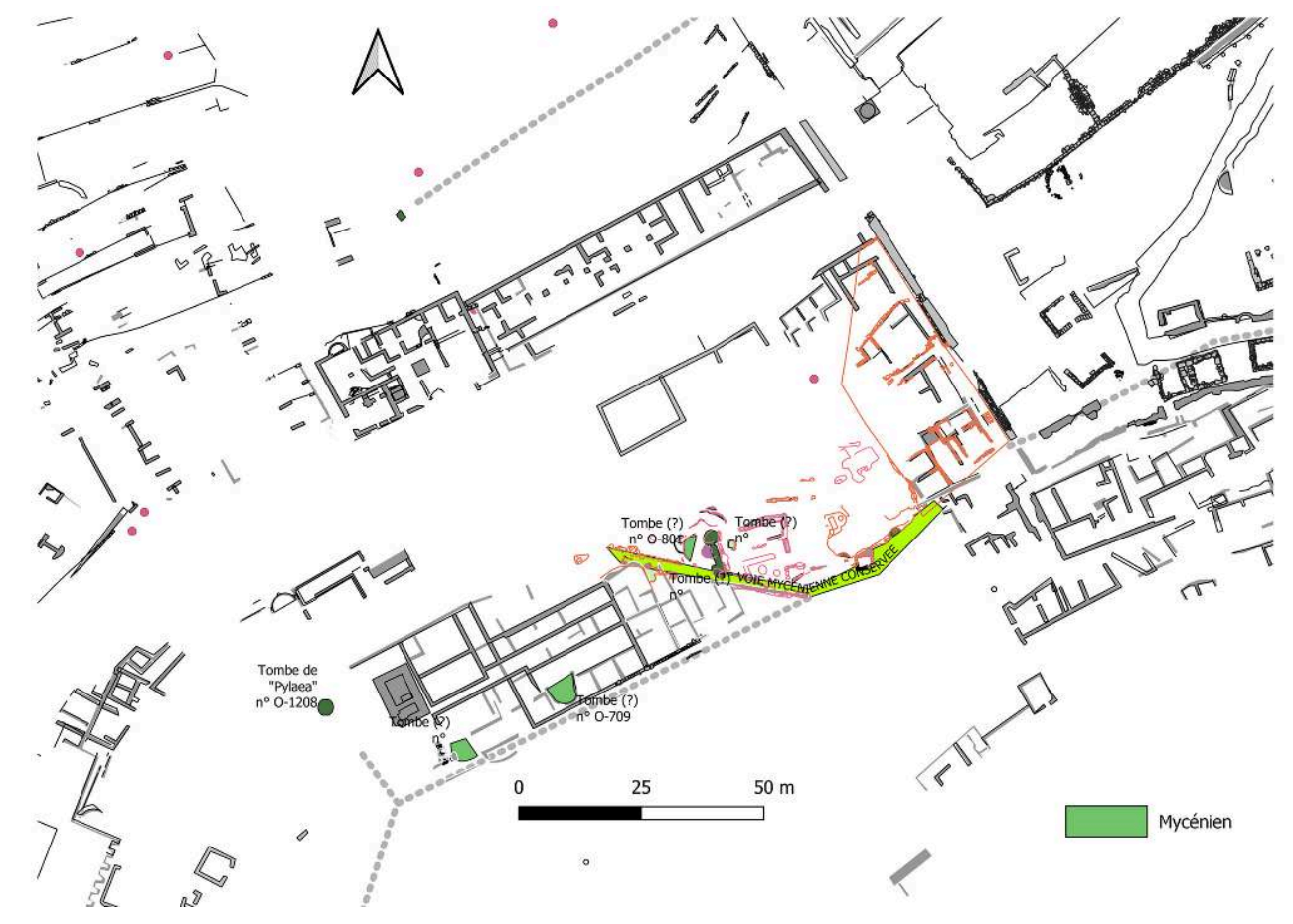

La voie mycénienne conservée en vert.

Jean-Marc Luce, Charlotte Goulet et Julian Brouet. 
Fig. 10. La voie mycénienne.

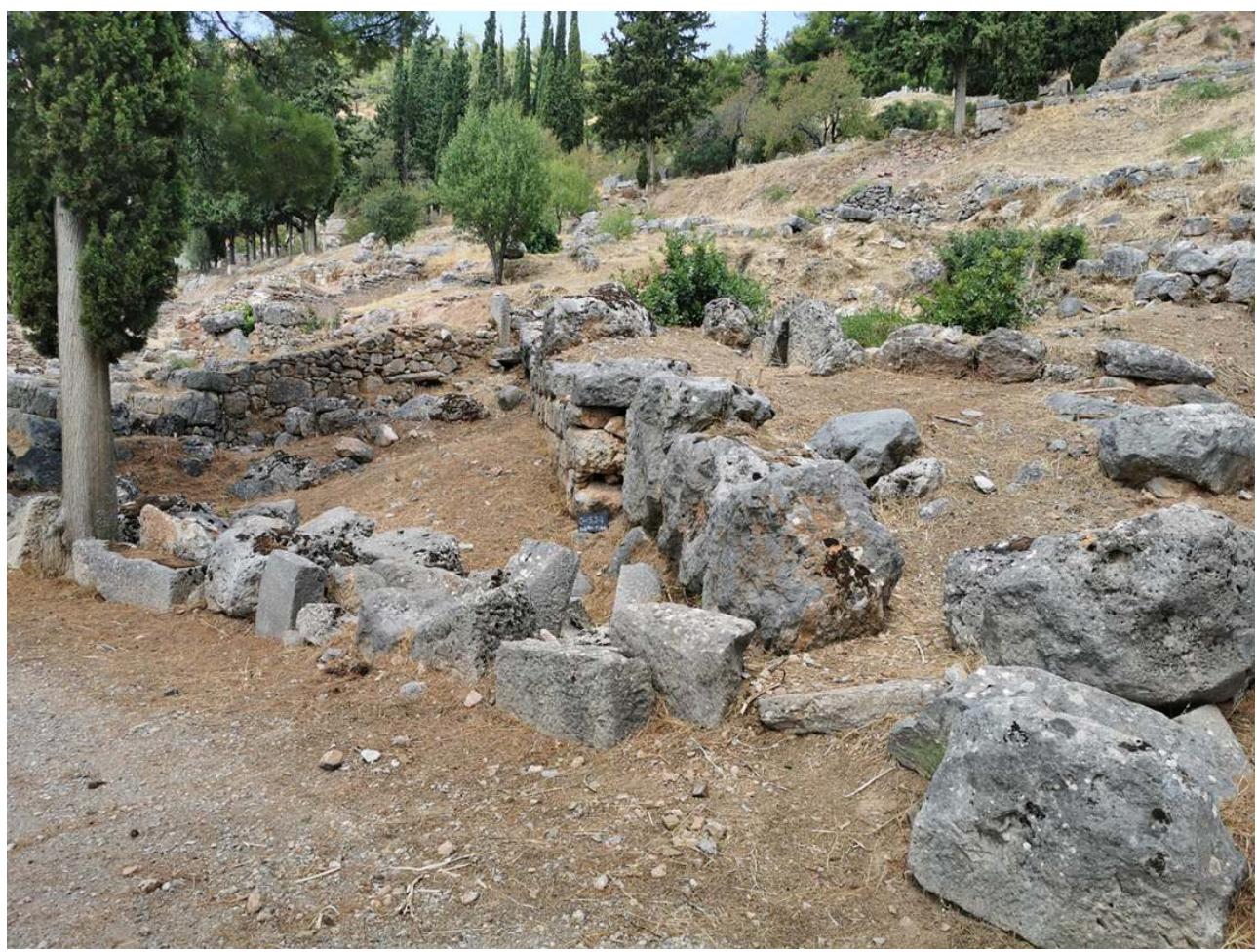

Cl. Jean-Marc Luce.

Fig. 11. Voie mycénienne, soutènement sud.

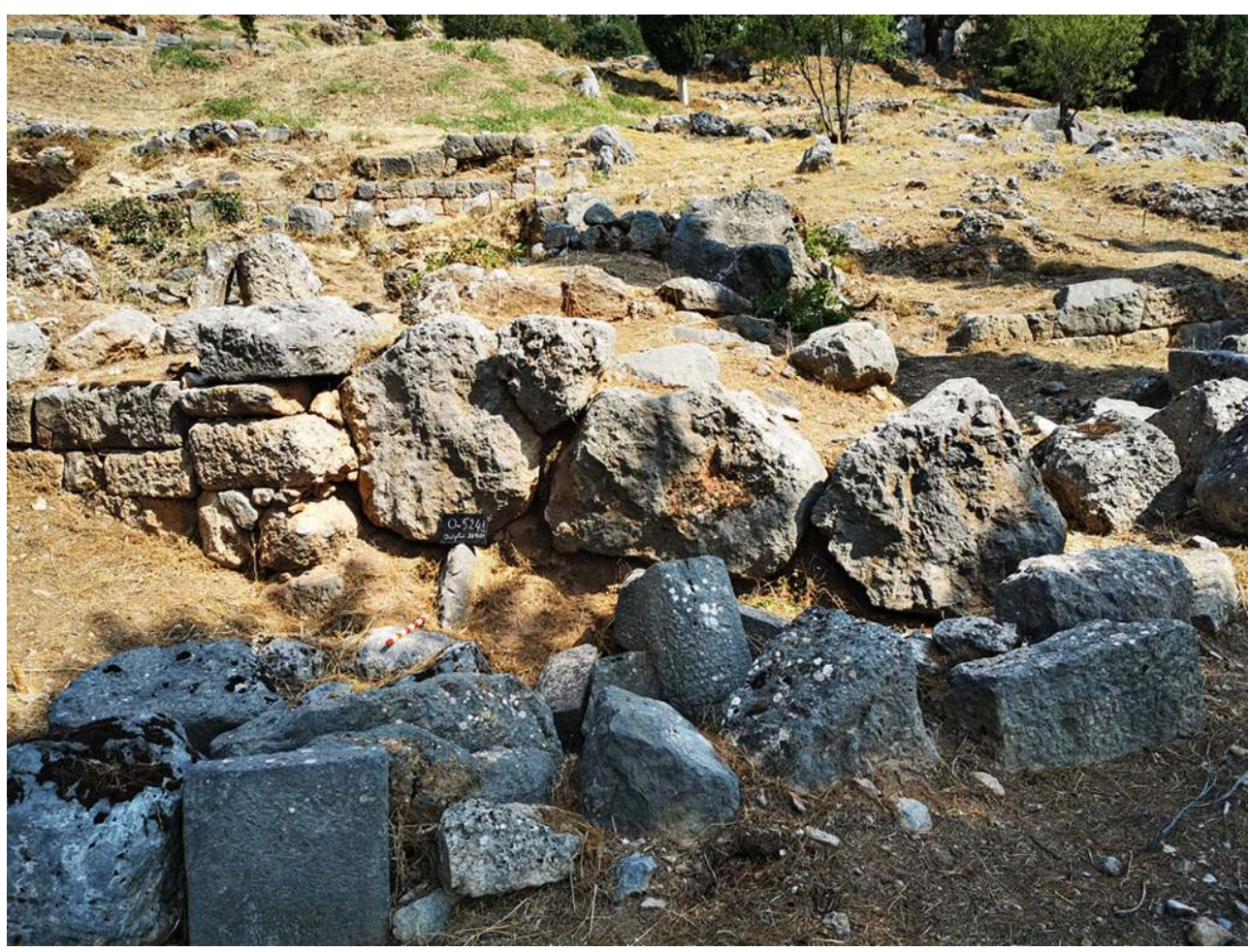

Appareil cyclopéen à droite.

Cl. Jean-Marc Luce. 
Fig. 12. Soutènement Nord de la voie mycénienne.

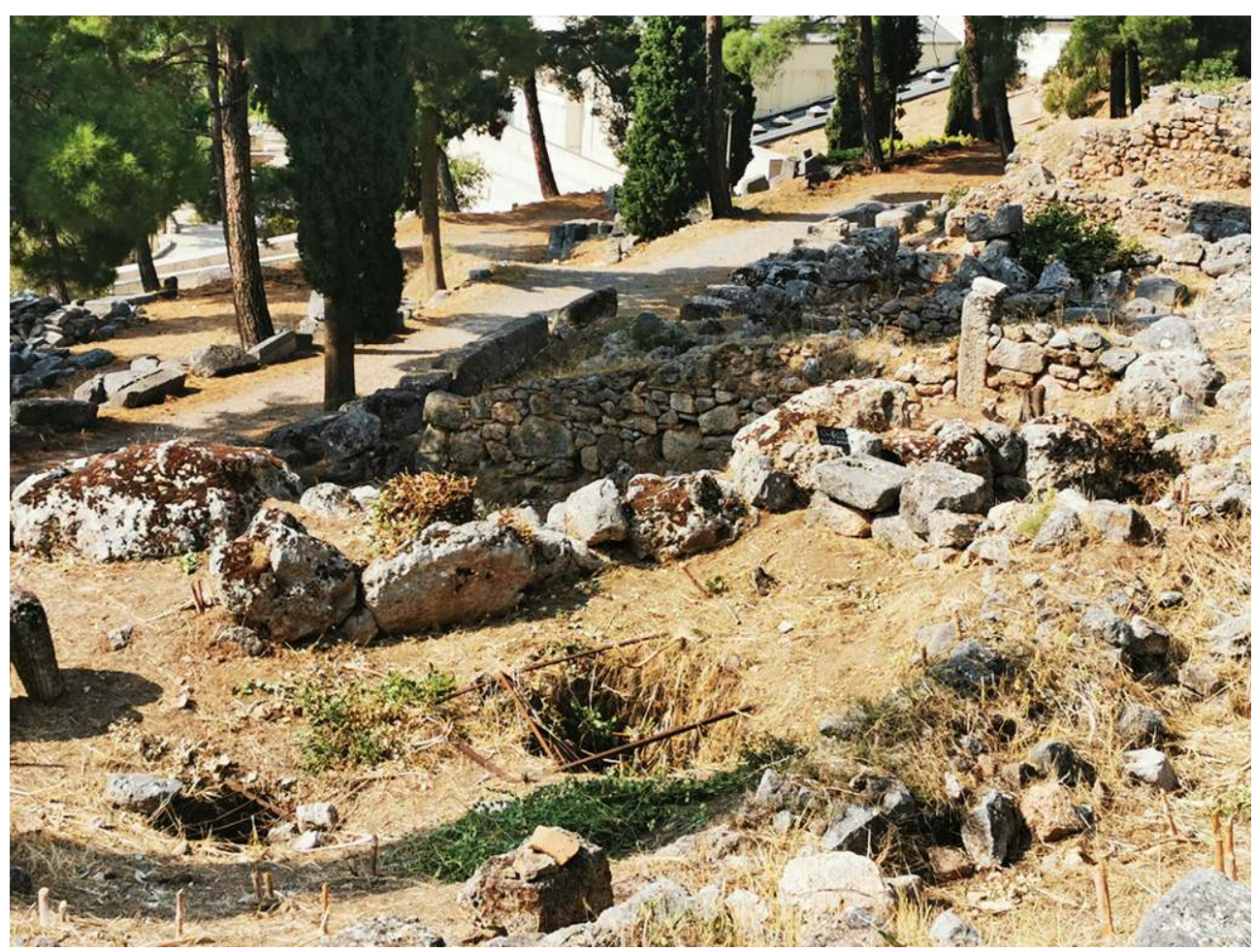

Cl. Jean-Marc Luce.

\section{Période archaïque à paléochrétienne}

10 La campagne d'inventaire a permis d'identifier les murs qui peuvent remonter à l'époque archaïque (fig. 13 et 14). Il s'agit principalement de constructions en appareil polygonal à joints courbes, certaines en grand appareil lesbien. Nous sommes donc dans la seconde moitié du vi ${ }^{\mathrm{e}}$ s., ou au début du ve s. av. J.-C. L'apport le plus important de notre recherche concerne les murs 0-704 et 0-703 qui délimitent, au Sud du quartier de l'Hérôon de Blum la voie qui lui donnait accès (fig. 13-16). Celle-ci était maintenue au Sud par 0-523, puis, à l'époque paléochrétienne, par le 0-707 et 0-708, tandis que la bordure Nord, sur laquelle s'appuyaient les maisons étaient délimitée par 0-701, puis 704 (1 à 5), enfin 0-707. Comme vu ci-dessus, cette rue remonte à l'époque mycénienne, et manifestement, certaines tombes ouvraient sur elle. Si aucune trace ne remonte à l'époque géométrique ni au début de l'époque archaïque, 0-703 et le soubassement de 0-704 (= 0-704.1 et 3) datent manifestement de la fin de l'époque archaïque. 
Fig. 13. Plan des vestiges de la zone à l'époque archaïque.

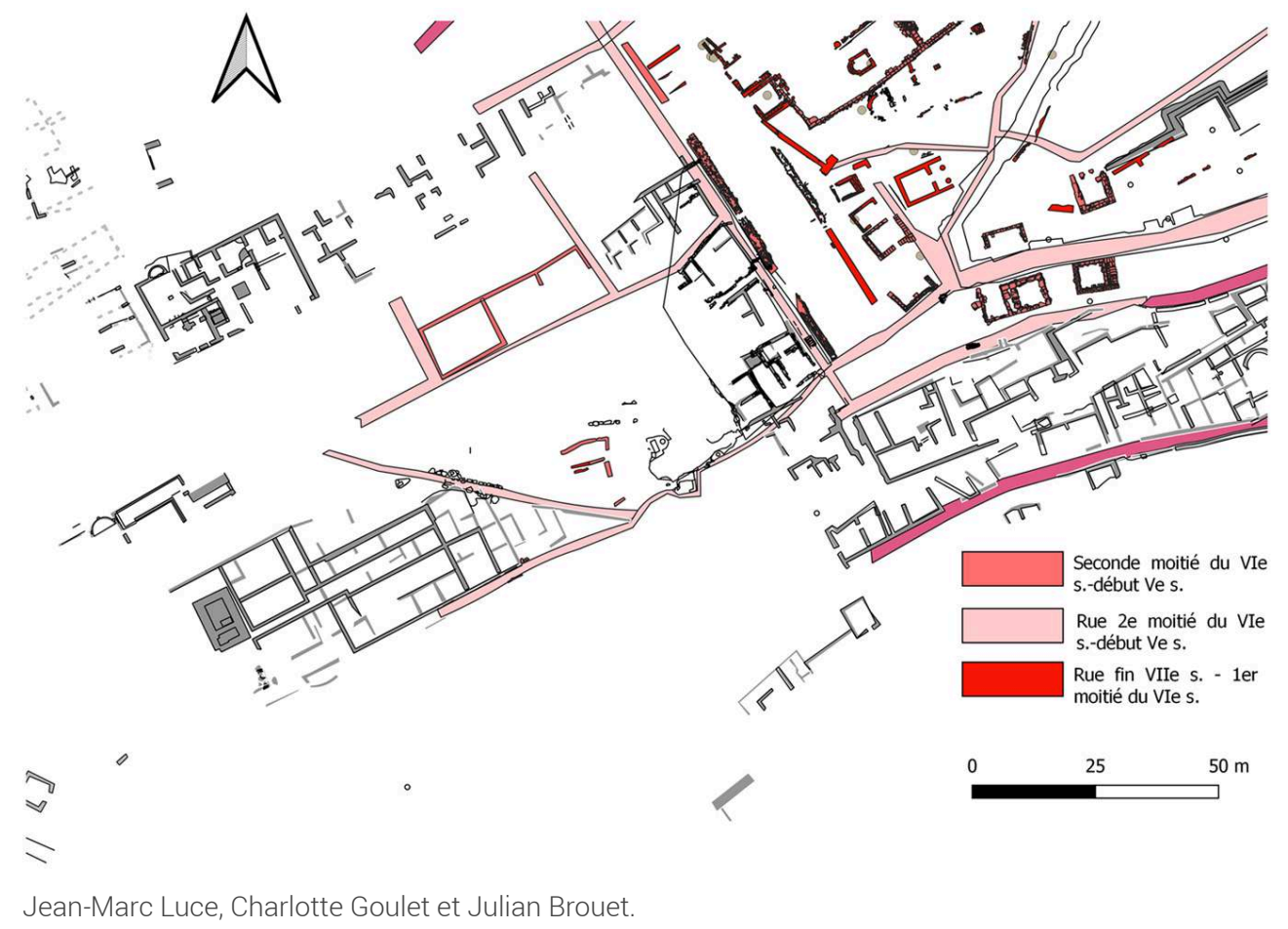

Fig. 14. Partie Est du quartier de l'hérôon de Blum, avec les soutènements archaïques de la rue au Sud (0-704 et 0-703).

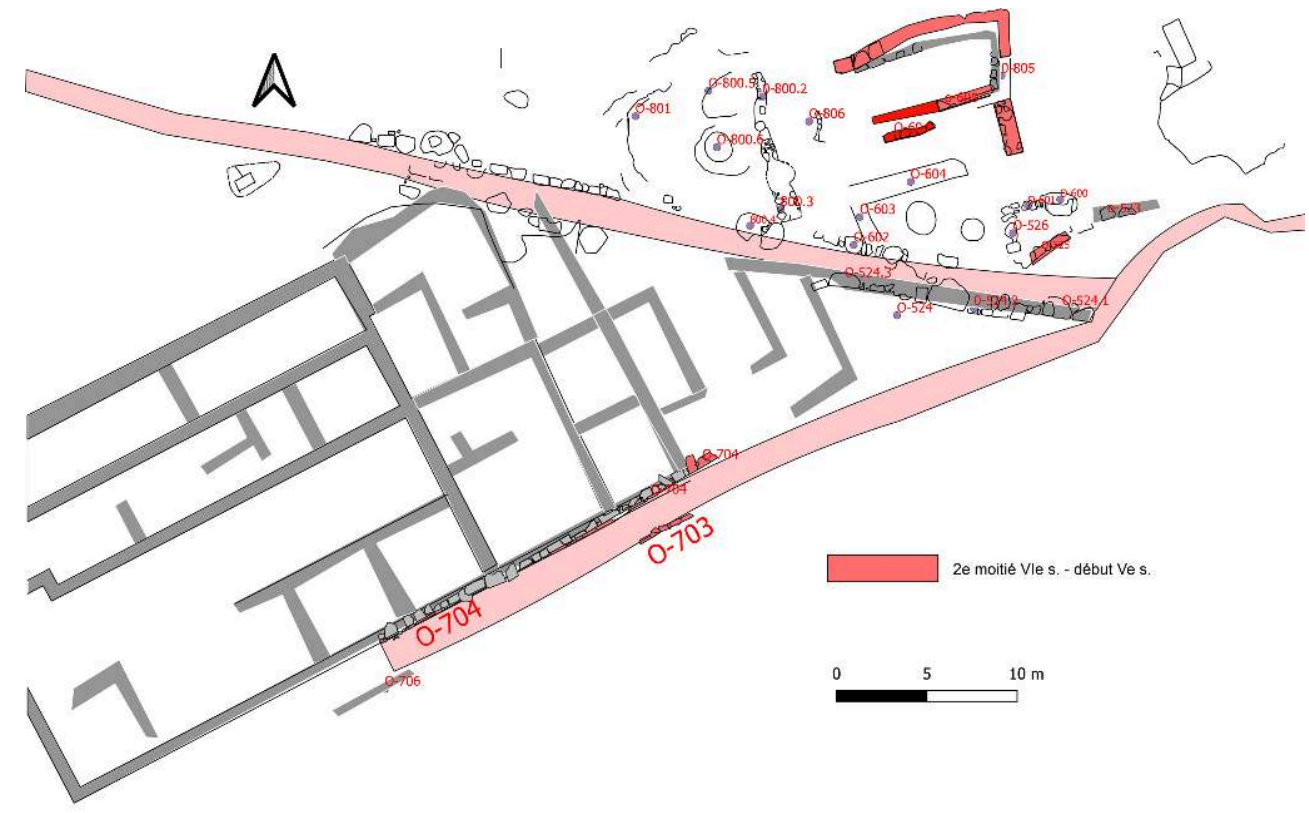

Jean-Marc Luce, Charlotte Goulet et Julian Brouet.

11 À l'époque classique, le mur 0-704 a été reconstruit dans un bel appareil trapézoïdal (0-704.2, fig. 15-18). La tête du mur à l'Ouest correspond exactement à la limite Ouest des murs classiques dans le quartier de l'hérôon de Blum (fig. 18). On peut en déduire que ce point correspond à la limite extrême de ce quartier à l'époque archaïque et classique, et que les prolongements vers l'Ouest sont plus récents. Ils se sont faits en au 
moins deux phases, l'une marquée par un appareil régulier en blocs de conglomérat, l'autre en un appareil de moellons pris dans du mortier de chaux avec des fragments de terre cuite architecturale. Il s'agit donc d'un prolongement de l'époque romaine et paléochrétienne, dont la première étape était sans doute la construction de l'hérôon de Blum, rejoint dans un second temps par la ville, à l'époque romaine tardive ou à l'époque paléochrétienne (voir ci-dessous).

Fig. 15. La rue desservant le quartier de l'hérôon de Blum (Est).

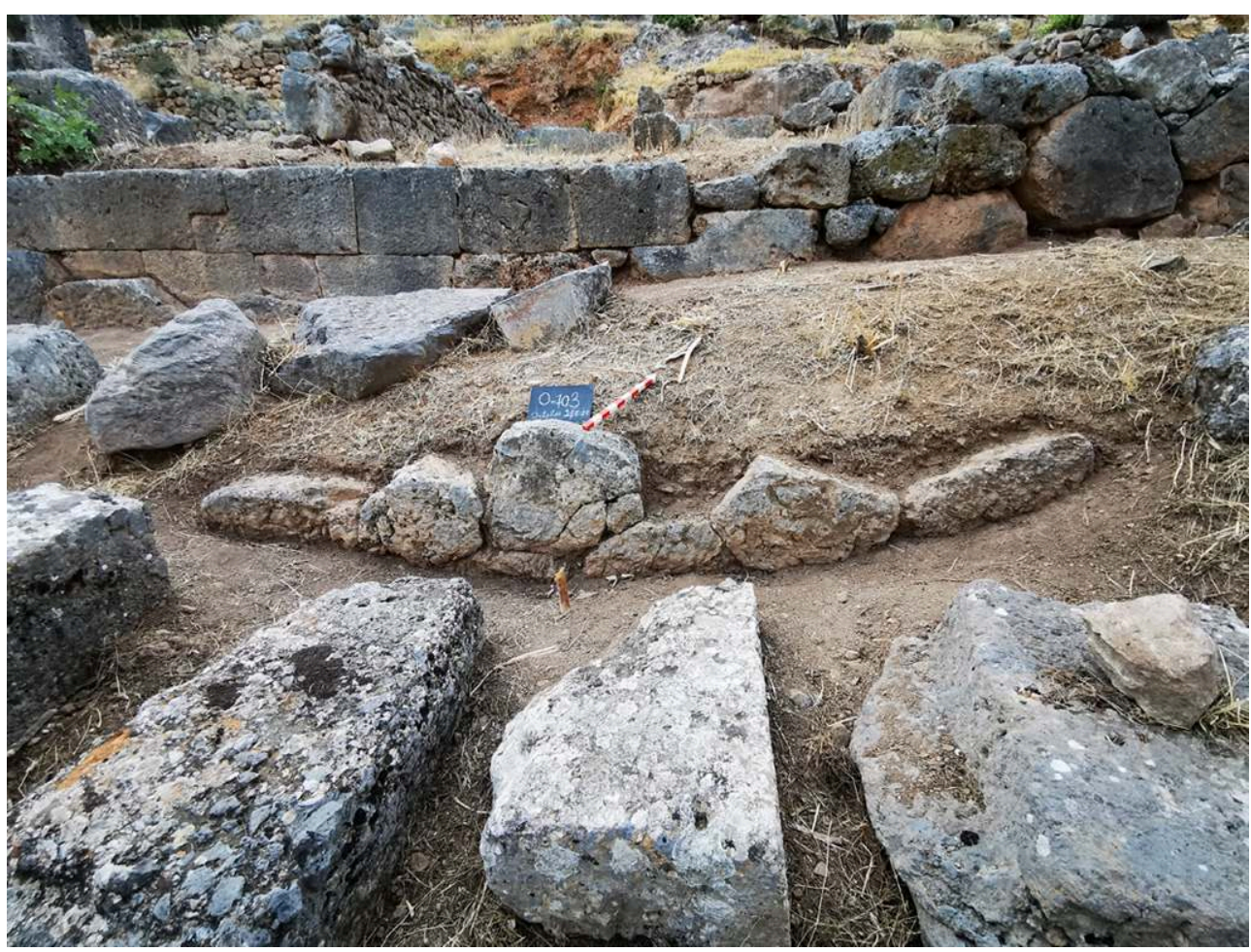

Au premier plan le soutènement sud de la voie, archaïque, et derrière le soutènement Nord, avec la partie Est restée dans l'état archaïque.

Cl. Jean-Marc Luce.

Fig. 16. Élévation de la partie Est du mur 0-704, avec l'état archaïque et l'état classique dessus.
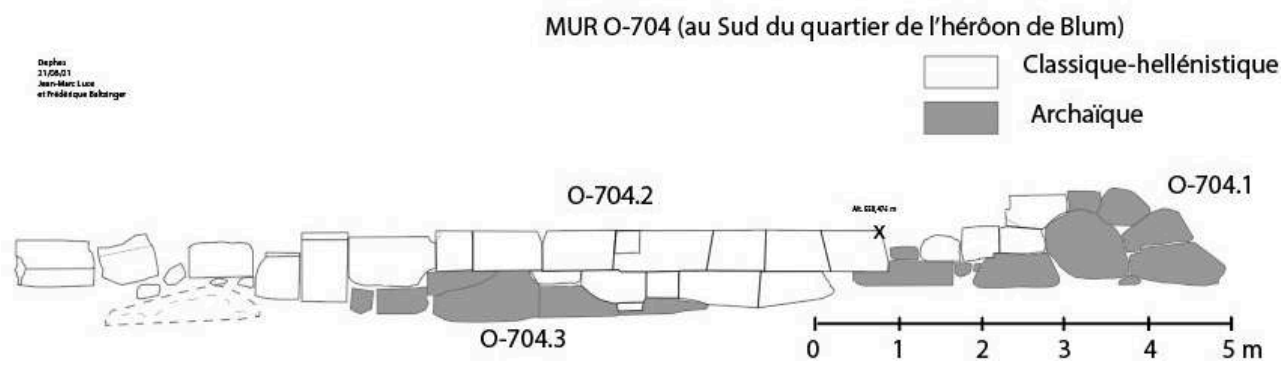

Frédérique Baltzinger. 
Fig. 17. La zone étudiée à l'époque classique-hellénistique.

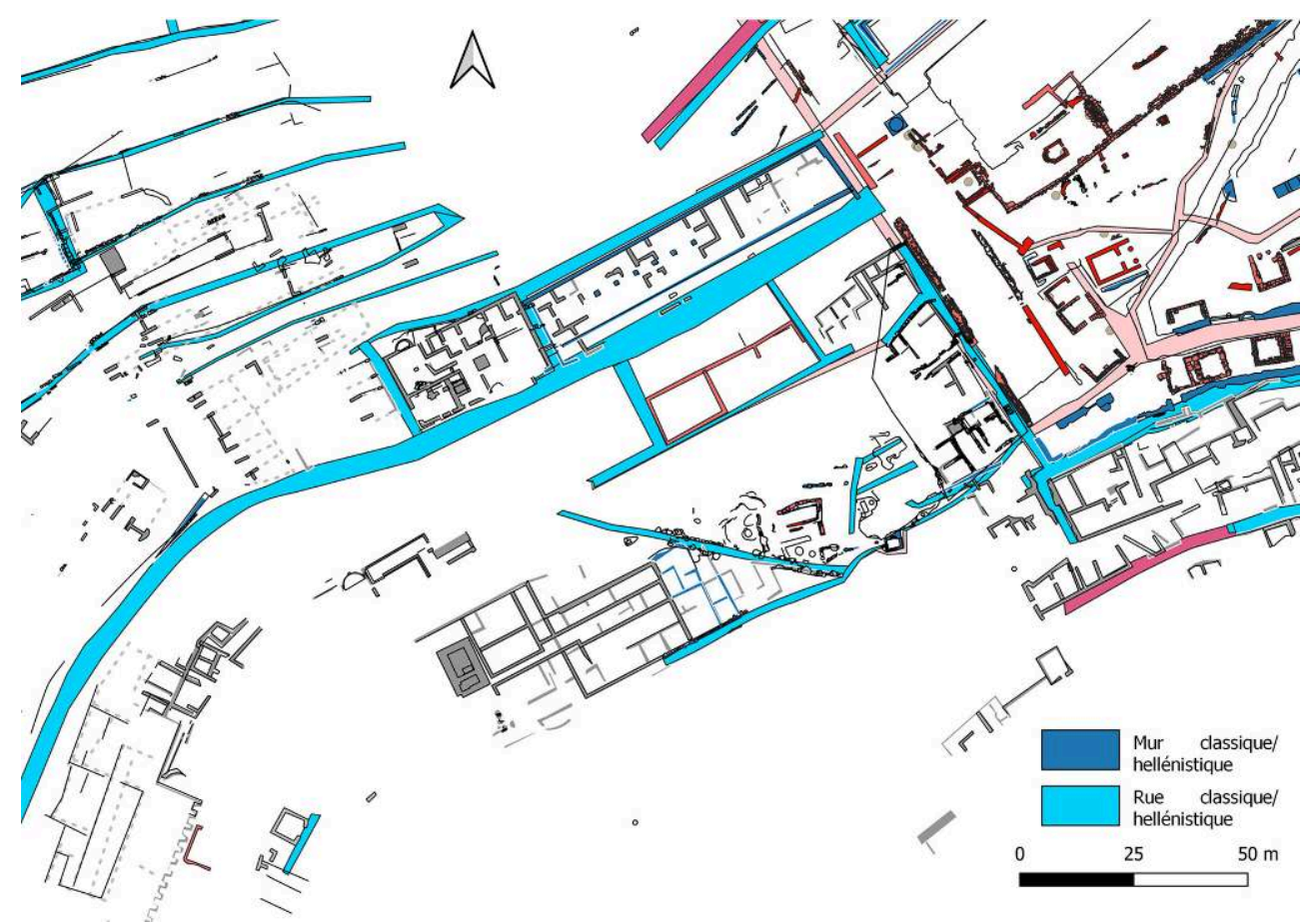

Jean-Marc Luce, Charlotte Goulet et Julian Brouet.

Fig. 18. L'Est du quartier de l'Hérôon de Blum.

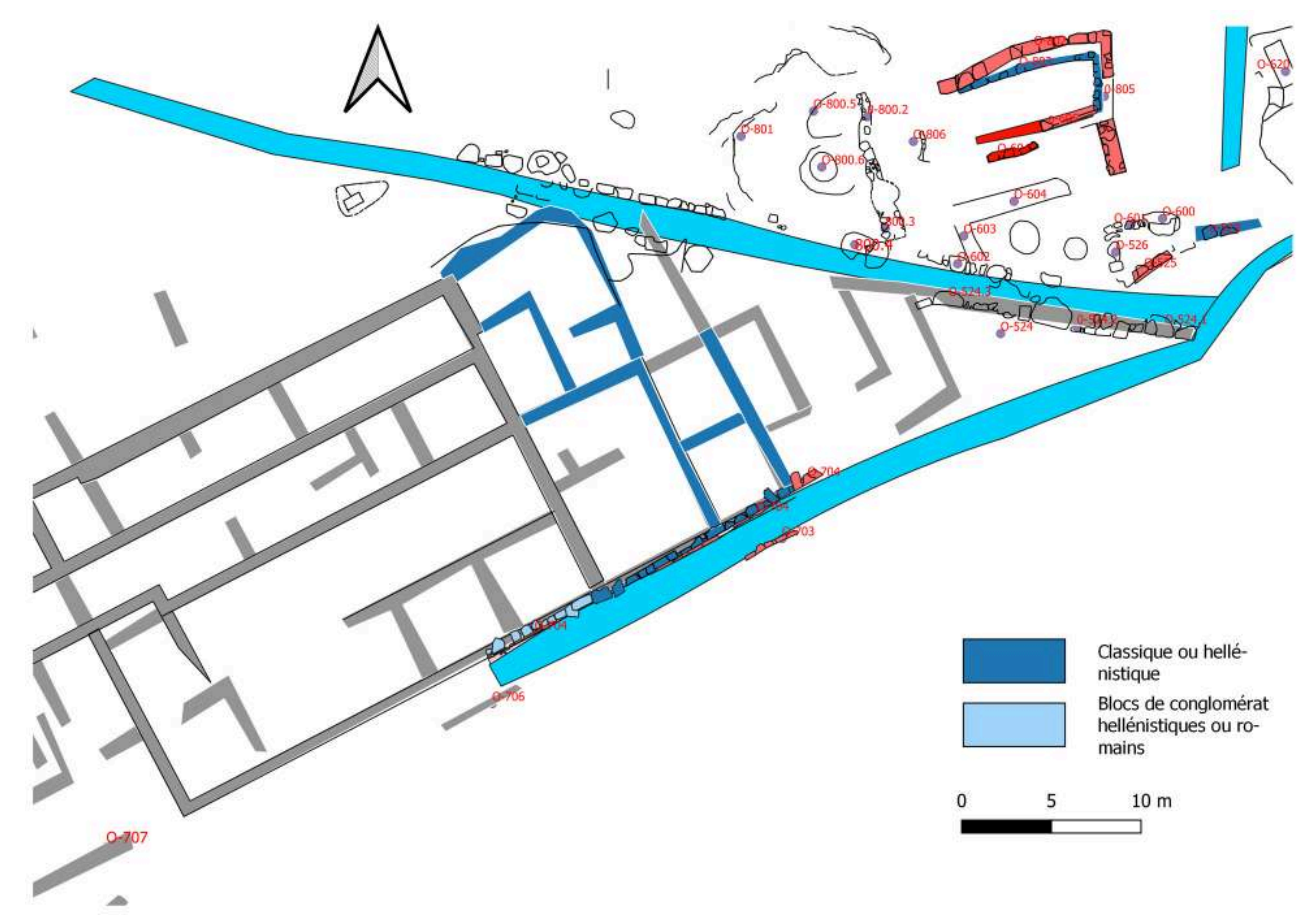

Dans le mur 0-704, en rouge les blocs archaïques, en bleu foncé, les blocs de calcaire de l'époque classique, à bleu clair à l'Ouest, les blocs de conglomérat de la phase 3 (hellénistique ou romain). Le mur se poursuit vers l'Ouest à l'époque romaine et paléochrétienne. La partie classique, en bleu s'interrompt là où les murs classiques du quartier, derrière le mur, s'interrompent également. Toute la partie Ouest est romaine-paléochrétienne.

Jean-Marc Luce, Charlotte Goulet et Julian Brouet. 
Fig. 19. Plan de la zone avec la fontaine rupestre et les rochers entaillés.

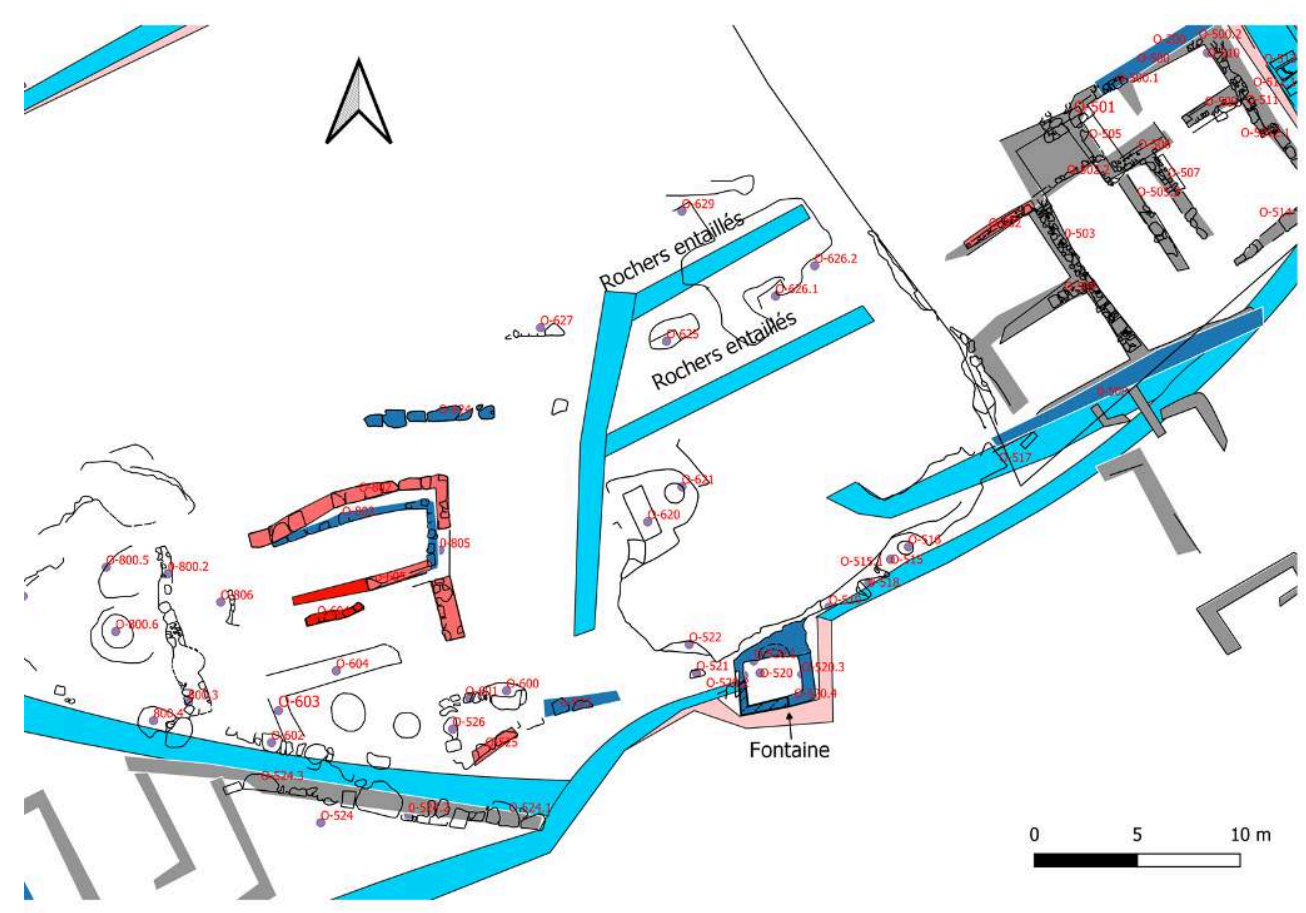

Jean-Marc Luce, Charlotte Goulet et Julian Brouet.

12 Cette rue longeant le Sud du quartier de l'Hérôon permettait aussi, durant l'époque historique, de s'approvisionner en eau. En effet, le long de la voie, entre les tombes mycéniennes 0-516 et 0-522, le roc a été entaillé, en sorte qu'il présente une paroi verticale en arrière d'une banquette (fig. 19-20). Au pied de cette dernière, un nettoyage a fait apparaître un bassin enduit. Il s'agit donc d'une fontaine dont la banquette devait supporter un réservoir entièrement taillé dans le roc (sauf peut-être la face Sud). Mais les parois Ouest, Sud et une partie de la paroi Ouest ont été rabattues à une époque ultérieure, peut-être à l'époque où l'on construisit le mur en appareil polygonal à joints droits $0-523$, juste à l'Ouest, dont on peut voir un encastrement contre la face Ouest du réservoir de la fontaine. Dans ce cas, la fontaine serait antérieure, mais cela reste à confirmer. 
Fig. 20. Zone des rochers entaillés, avec restitution des voies de circulation.

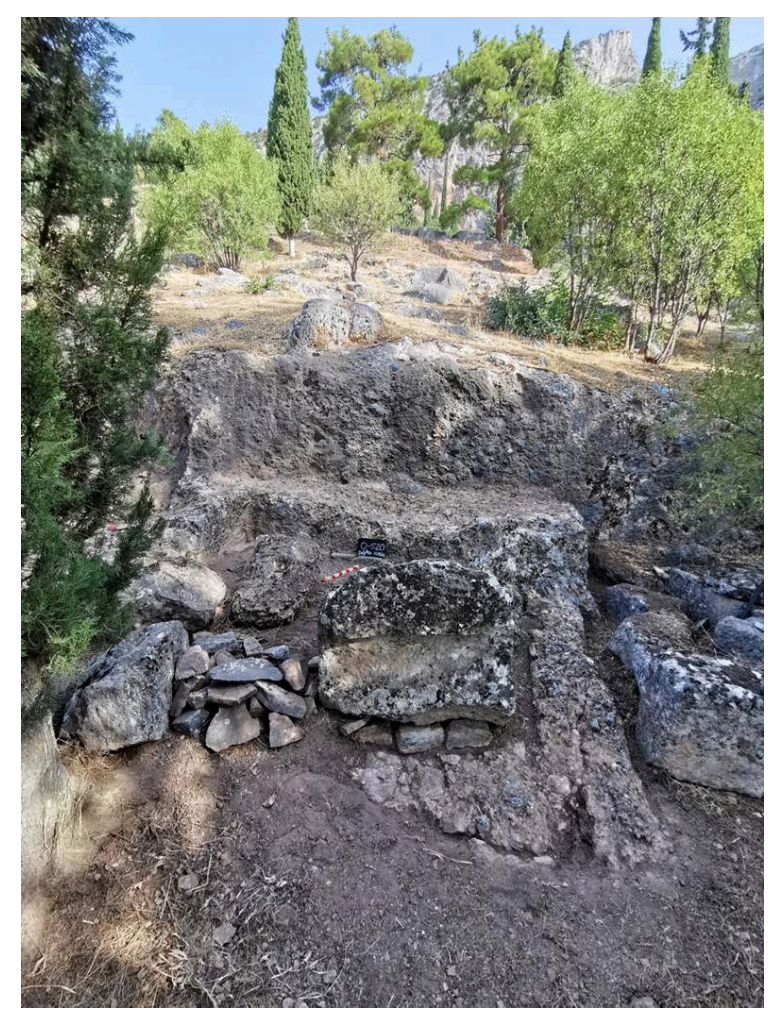

Au Nord de la voie la plus au Nord, des encastrements de poteaux ont été décelés, mais n'ont pu être relevés.

Cl. Jean-Marc Luce.

13 C'est aussi durant l'époque historique, probablement durant l'époque classique, qu'ont été creusés une série d'encastrements dans la zone II, dans la colline entre les terrasses proches du péribole et le quartier de l'hérôon de Blum (fig. 19, 20). Ils se répartissent sur trois terrasses superposées. Les encastrements 0-628 (non relevé) et 0-629 de la terrasse supérieure, étant alignés, doivent correspondre à un mur de terrasse ou à la façade d'une construction. Devant ces derniers, de petits encastrements indiquent la présence de poteaux devant le mur (fig. 21). Nous avons donc affaire à un appentis ou à une maison à pastas (si le mur 0-628-629 était la façade d'une construction et non le simple mur arrière de l'appentis). La terrasse moyenne montre aussi des espaces aménagés dans le roc, deux au moins (0-626.1 et 2, qui ouvraient sur un espace). Plus au Sud, un encastrement dans le rocher 0-623 (non relevé) supportait aussi un poteau en bois, mais la relation avec 0-626 est incertaine, car il ne se trouve pas au même niveau. La terrasse inférieure (0-620 et 0621), et le mur 0-619 qui rejoignait l'encastrement 0-622 forment un ensemble de l'époque paléochrétienne. Le creusement 0-620 en baignoire rectiligne, orienté Est-Ouest, était recouvert d'un enduit peint avec des bandeaux rouges verticaux. Il s'agit probablement d'une tombe. 
Fig. 21. Rochers taillés pour recevoir un mur.

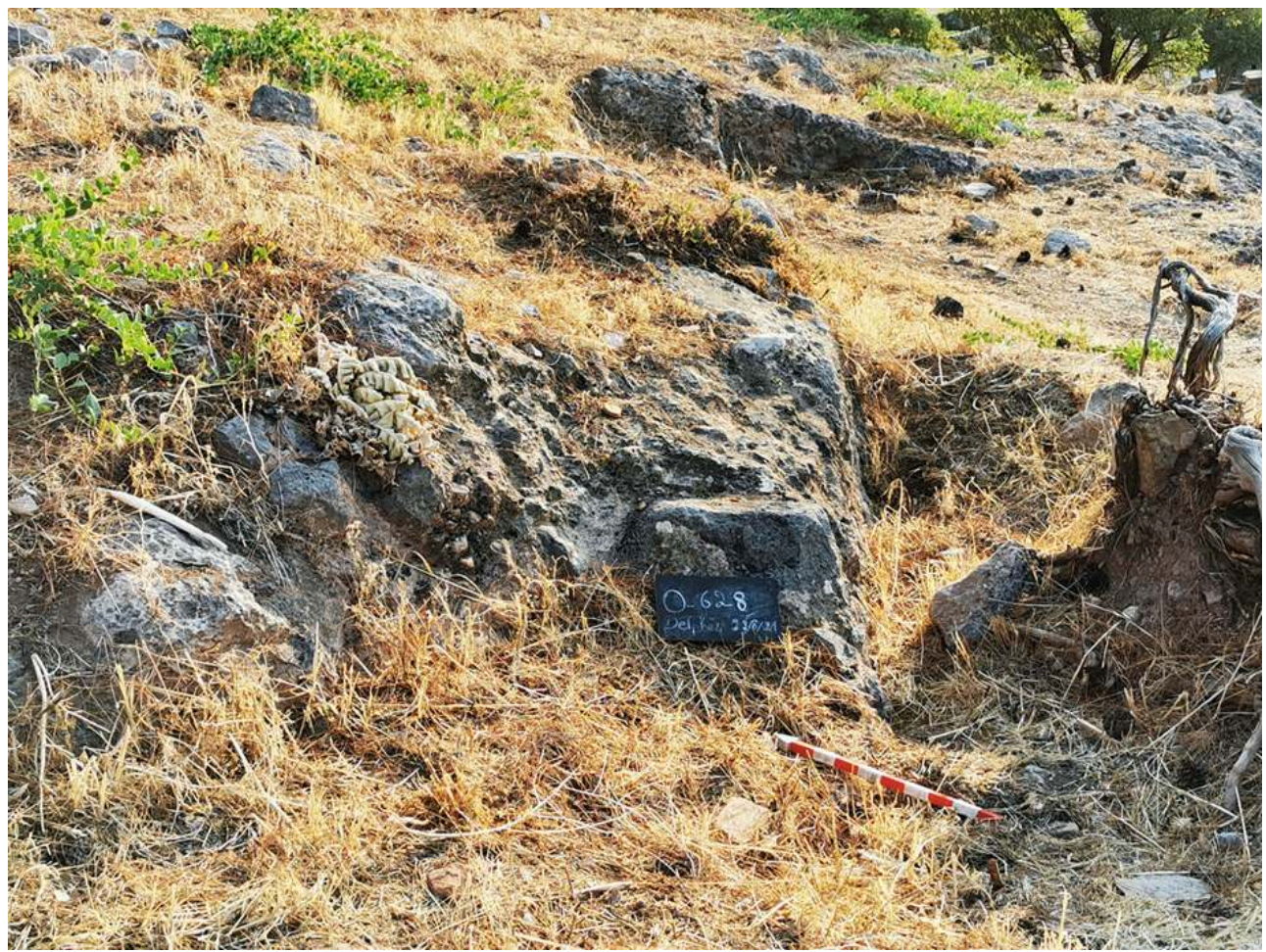

Cl. Jean-Marc Luce.

Fig. 22. Encastrement d'un pilier en bois taillé dans le roc.

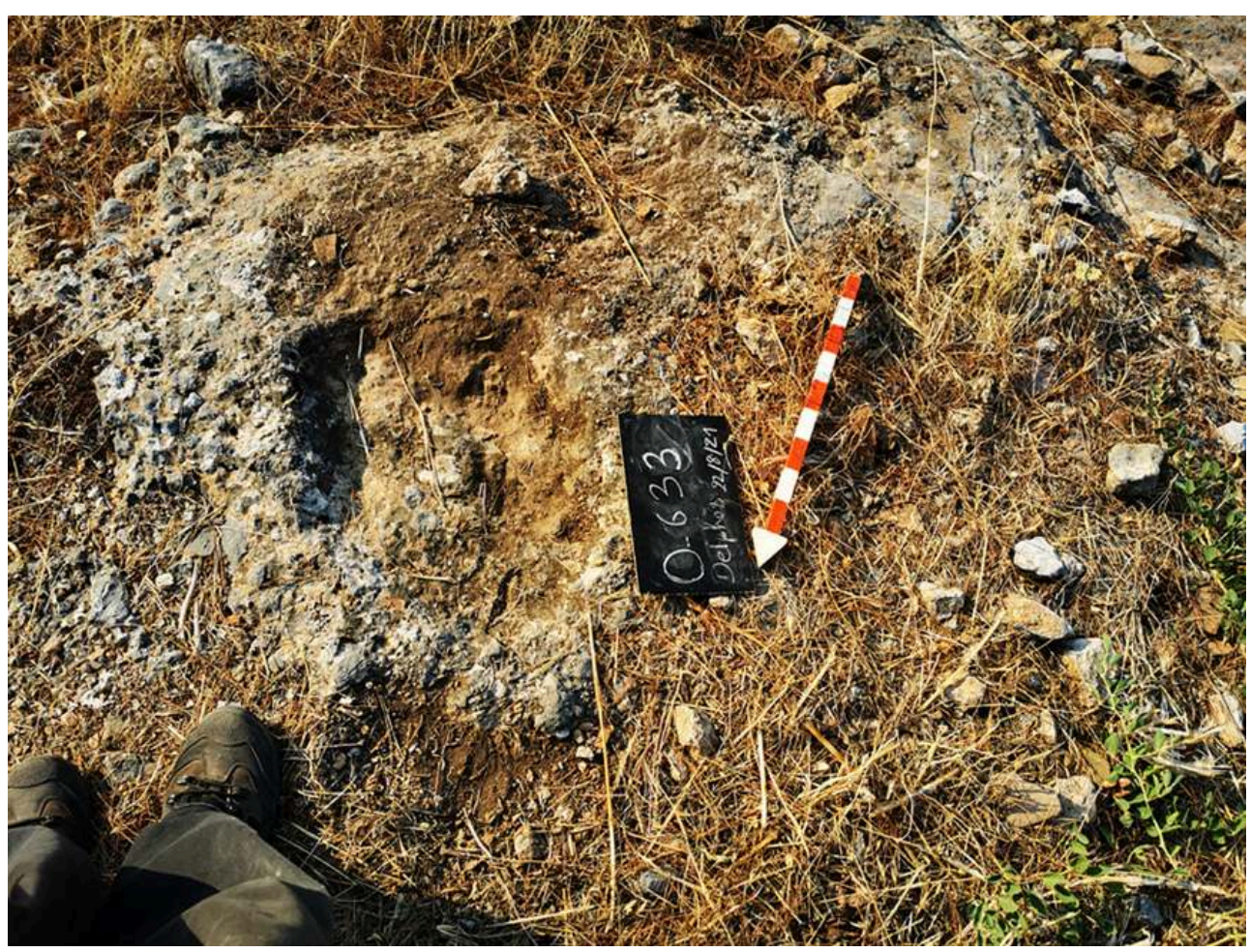

Cl. Jean-Marc Luce. 
Quoi qu'il en soit, tous ces creusements étaient nécessairement accessibles par des passages Est Ouest. On accédait à ce quartier par deux voies conservées sur le terrain. La première, à l'Est, était bordée par le mur 0-508. L'autre était une voie avec des marches d'escalier, montant depuis le Sud Est.

Fig. 23. L'escalier conduisant à l'Hérôon de Blum.

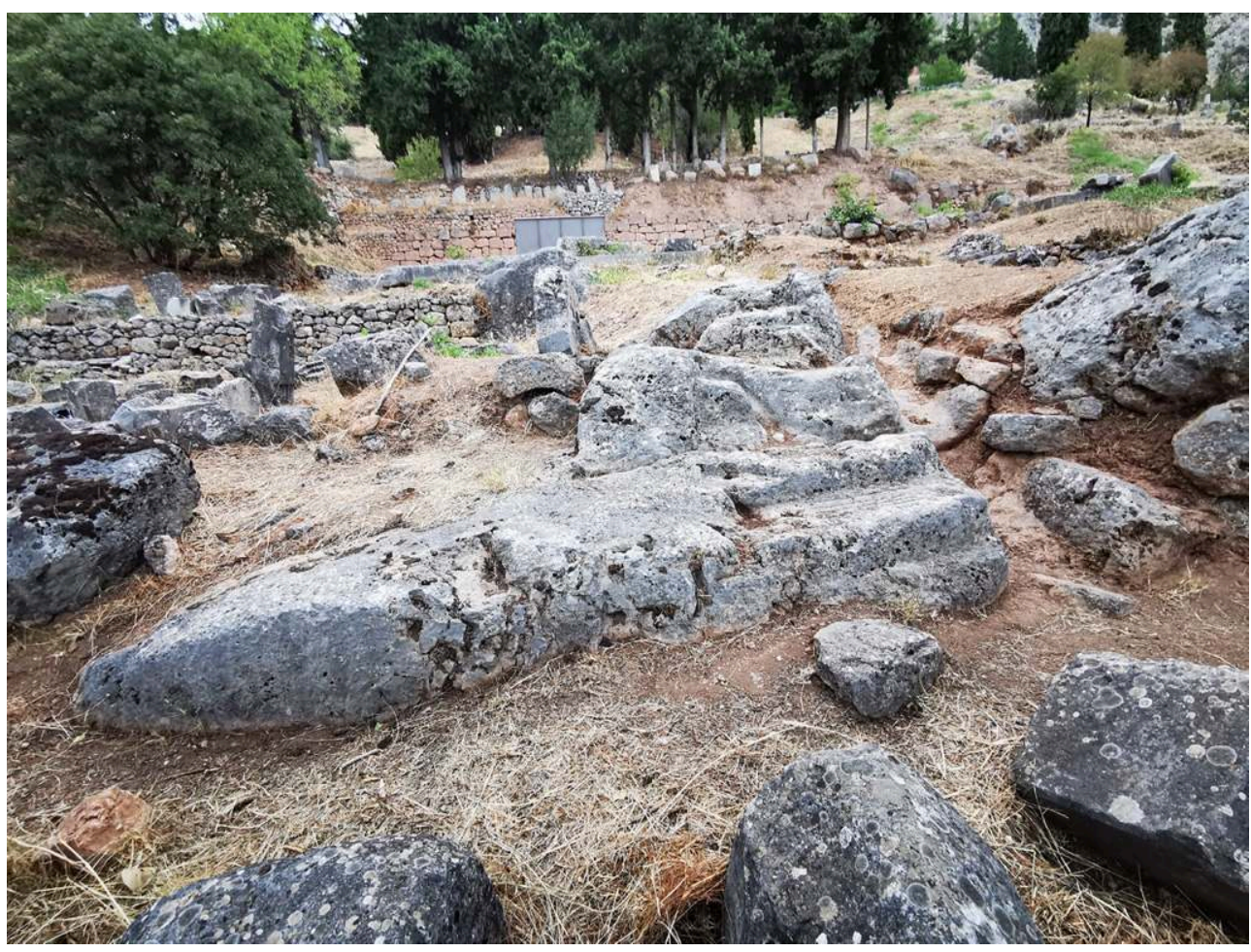

La porte de fer ouverte est la trappe fermant la chambre funéraire.

Cl. Jean-Marc Luce.

Enfin signalons, à l'extrémité Ouest, le relevé de l'escalier qui, depuis la rue de l'hérôon, conduisait à son monument éponyme, le dit "Hérôon de Blum", ce tombeau du $\mathrm{I}^{\mathrm{er}}$ siècle de notre ère, à l'élévation semblable à celle d'un temple. Comme l'accès au monument depuis le quartier dont il occupe l'extrémité Ouest était limité à $35 \mathrm{~cm}$, du moins à l'époque paléochrétienne, on peut penser que cet escalier constituait l'accès principal. Il était bordé à l'Est d'un caniveau creusé dans le roc.

\section{Conclusion}

Cette campagne courte (trois semaines dont seulement deux avec une équipe complète) a permis de dresser un plan bien plus précis de la zone étudiée, à l'échelle 1:50, d'apporter d'importants compléments à ceux dont on disposait déjà. Nous pouvons ainsi proposer un plan de la nécropole Ouest de l'époque mycénienne, qui contenait probablement beaucoup plus de tombes que ne l'avait imaginé Perdrizet. Les phases d'extension du quartier de l'hérôon de Blum ont pu être précisées.

17 La campagne a également permis de faire de nouvelles découvertes, les unes assurées, d'autres plus hypothétiques :

- La rue mycénienne reliant deux tombes de cette époque, étonnamment bien conservée ; 
- L'identification de nouvelles tombes mycéniennes, encore hypothétique, mais très probable pour certaines d'entre elles ;

- La découverte d'une fontaine rupestre ;

- La découverte de structures avec une galerie ouverte : appentis ou maison(s) ;

- Plusieurs rues archaïques et classiques ont pu être identifiées.

\section{BIBLIOGRAPHIE}

MÜLLER 1992

Sylvie Müller, « Delphes et sa région à l'époque mycénienne », BCH 116.2, 1992, p. 445-496.

PERDRIZET 1908

Paul Perdrizet, FD V. Monuments figurés : petits bronzes, terres cuites, antiquités diverses, Athènes,

Paris, EFA, 1908.

\section{NOTES}

1. PERDRIZET, 1908 , p. 6-7, fig. 16 ; MÜLLER 1992, p. 493, nº 25

2. PERDRIZET 1908, p. 6-7, fig. 17 ; MÜLLER 1992, p. 493, nº 25

3. PERDRIZET 1908, p. 6-7, fig. 15, qui en a donné un plan détaillé ; MÜLLER 1992, p. 493, $n^{\circ} 25$

4. MÜLLER 1992, p. 493, nº 26.

5. MÜLLER 1992, p. 493, nº 27.

6. MÜLLER 1992, p. 493, nº 28 et 29.

\section{INDEX}

\section{Thèmes : EFA}

Année de l'opération : 2021

chronologie https://ark.frantiq.fr/ark:/26678/pcrtW9SpIgIk7Q

lieux https://ark.frantiq.fr/ark:/26678/pcrtctXS0kARjk

sujets https://ark.frantiq.fr/ark:/26678/pcrtF9P4mbuyGk, https://ark.frantiq.fr/ark:/26678/ pcrtJFgfi13Ejz, https://ark.frantiq.fr/ark:/26678/pcrtVZj9m4AOTE, https://ark.frantiq.fr/ark:/ 26678/pcrtYmIa7MvtLc, https://ark.frantiq.fr/ark:/26678/pcrtbptj4SOA1W, https:// ark.frantiq.fr/ark:/26678/pcrtsIm3RuNMGu, https://ark.frantiq.fr/ark:/26678/pcrtOjL41tGiRu, https://ark.frantiq.fr/ark:/26678/pcrt1eKrSANesO 